\title{
Influence of Follicular Fluid on in Vitro Maturation and Fertilization of Bovine Oocytes
}

\author{
Ignacio Covelo, Marcos Alejandro Puente, Carmen Mabel Tartaglione* \\ Laboratory of Animal Reproduction, National University of Lomas de Zamora, Buenos Aires, Argentina \\ Email: *dramabeltartaglione3@gmail.com
}

How to cite this paper: Covelo, I., Puente, M.A. and Tartaglione, C.M. (2022) Influence of Follicular Fluid on in Vitro Maturation and Fertilization of Bovine Oocytes. Open Journal of Animal Sciences, 12, 118-128. https://doi.org/10.4236/ojas.2022.121009

Received: December 14, 2021

Accepted: January 24, 2022

Published: January 27, 2022

Copyright $\odot 2022$ by author(s) and Scientific Research Publishing Inc. This work is licensed under the Creative Commons Attribution-NonCommercial International License (CC BY-NC 4.0). http://creativecommons.org/licenses/by-nc/4.0/ (c) (i) (8) Open Access

\begin{abstract}
The aim of this study was to investigate the effect of time on in vitro maturation of bovine oocytes and of the addition of follicular fluid on meiotic progression. The cumulus-oocyte complexes (COCs) collected from 3 to $6 \mathrm{~mm}$ follicles were obtained from ovaries of slaughtered female animals. The medium of maturation was supplemented or not with $20 \mu \mathrm{L}$ follicular fluid (FF); 661 oocytes were matured in vitro (extrusion of the first polar corpuscle) for 22 hours with added follicular fluid (AFF) $(72.01 \%)$ or without follicular fluid (WFF) (67.53\%) and 679 oocytes were matured in vitro for 26 hours (extrusion of the first polar corpuscle) with AFF (92.1\%) and WFF (77.15\%). The results of extrusion of the second polar corpuscle as an event related to the fertilization percentages showed that the increase in the fertilization rate is maintained at 26 hours with AFF (79.45\%), but the percentage decreases WFF (65.08\%). After 22 hours, the fertilization rate was $62.38 \%$ AFF and $53.40 \%$ WFF. The developmental competence of bovine oocytes is affected by the duration of maturation in vitro and the inclusion in the FF culture medium. The use of follicular fluid in the in vitro maturation medium may be a biological strategy to increase the cumulus expansion, the nuclear maturation and the in vitro fertilization.
\end{abstract}

\section{Keywords}

Oocyte, In Vitro Maturation, In Vitro Fertilization, Follicular Fluid, Bovine

\section{Introduction}

It is known that a common in vitro maturation and fertilization strategy involves recovering bovine ovaries from the slaughterhouse and that these ovaries are in 
different stages of the oestrous cycle [1] [2]. Therefore, the developmental competence varies according to the oocyte quality [3]. The competence of oocyte maturation is influenced by several factors, such as ovarian status, follicle size, collection method, oocyte quality, culture conditions, aspiration pressure during collection, and time between collection and processing [4]. The quality of the oocytes is determined by their ability to mature, be fertilized, and give rise to normal offspring [5] [6]. Other important factors are transport temperature from slaughterhouse to laboratory, maturation time [7] and hormones [8]. These factors can affect the possibility of in vitro maturation of oocytes [9]. The ability of a mature oocyte to overcome the stages of fertilization and embryo development is called oocyte development capacity, and it is an intrinsic measure of its quality [6] [10]. In vitro matured oocytes have lower developmental competence than in vivo matured oocytes in part due to the inadequate in vitro environment that supports the full development of maturation [11] [12] [13]. There is a competition between oocytes, which is defined as the ability of an oocyte to develop throughout the different embryo stages in vitro. This ability has been examined in relation to follicular diameter because it is the first criterion used for the selection of oocytes for in vitro fertilization [10] [14] [15]. Most cumulus-oocyte complexes (COCs) collected from 3 to $6 \mathrm{~mm}$ follicles appear to mature in vitro, but many are not capable of producing blastocysts [6] [16] [17]. In addition, the FF is a vascular compartment within the mammalian ovary, separated from the perifollicular stroma by the follicular wall, which constitutes a blood-follicle barrier [18]. Since the resumption of meiosis and cytoplasmic maturation of bovine oocytes takes place in close association with FF, it would be logical to assume that fluid might be a perfect maturation medium [19] [20]. This fluid is composed of locally produced substances within the follicle, which are related to the metabolism of follicular cells [21]. The FF is the product of the transfer of blood plasma components through the blood-follicular barrier and of the metabolism of theca and granulosa cells [22] [23]. It corresponds to a complex mixture of electrolytes, proteins, hormones, such as testosterone, estradiol-17 $\beta$ (E2), and progesterone (P4), growth factors, nutrients and other molecules [24] [25] [26]. It is a slightly viscous solution with $\mathrm{pH} 7.4$ [24]. The FF maintains a proper environment for the growth and maturation of oocytes, besides meeting the nutritional requirements of the growing oocytes [27].

\section{Materials and Methods}

Ovary collection and follicle classification:

A total of 400 ovaries were obtained on different days reaching 25 repetitions. In situ, the ovaries of the female reproductive tract were sectioned and placed in a thermos containing sterile saline and antibiotics $\left(100 \mathrm{IU} / \mathrm{cm}^{3}\right.$ penicillin, 100 $\mathrm{mg} / \mathrm{cm}^{3}$ streptomycin) at $36^{\circ} \mathrm{C}$. Then, they were transported to the laboratory within $30 \mathrm{~min}$ after the animals were slaughtered. Oocyte aspiration was performed with a 5 or $10 \mathrm{~cm}^{3}$ syringe and an $18 \mathrm{G}$ sterile hypodermic needle. Then 
the follicular fluid was stored in a $15 \mathrm{~cm}^{3}$ Falcon tube in a thermostatic bath at $34^{\circ} \mathrm{C}$ and, after decanting for a few minutes, they were placed in Petri dishes for observation. The oocytes were selected using a magnifying glass by evaluating their general appearance, cytoplasm, and the cumulus cells that surrounded them. Those oocytes that were completely surrounded by three or more compact layers of cumulus cells and presented homogenous ooplasms were classified as suitable and selected for in vitro maturation. By contrast, those that were surrounded by less than three strata of cumulus cells and non-compact cumulus and had heterogeneous or pyknotic ooplasms were classified as unsuitable (Figure 1).

Collection of follicular fluid

Based on the ovarian status or the follicular size, the follicular fluid (FF) was recovered from the antral follicle $(10-15 \mathrm{~mm})$ and centrifuged at $3000 \mathrm{rpm}$. The supernatant was collected, inactivated at $56^{\circ} \mathrm{C}$ for $30 \mathrm{~min}$. [27] [28]. The harvested $\mathrm{FF}$ was stored frozen at $-20^{\circ} \mathrm{C}$ in an Eppendorf tube containing $20 \mu \mathrm{L}$.

In vitro maturation

A total of 1340 oocytes were selected and washed three times in HEPES Tyrode's albumin-lactate-pyruvate (TALP) medium plus HEPES $\left(25 \mathrm{mM} / \mathrm{cm}^{3}\right)$ and $3 \mathrm{mg} / \mathrm{cm}^{3}$ bovine serum albumin (BSA). A minimum of $8-10$ COCs were cultured into a Petri dish containing droplets of TCM-199 (50 $\mu \mathrm{L})$ fortified with sodium pyruvate $\left(0.2 \mathrm{mg} / \mathrm{cm}^{3}\right)$, fetal calf serum $(10 \% \mathrm{v} / \mathrm{v})$, FSH $\left(1 \mu \mathrm{g} / \mathrm{cm}^{3}\right), \mathrm{LH}(1$ $\left.\mu \mathrm{g} / \mathrm{cm}^{3}\right)$, E2 $\left(1 \mu \mathrm{g} / \mathrm{cm}^{3}\right)$ with added follicular fluid (AFF) $(20 \mu \mathrm{L}), \mathrm{n}: 661$ and without follicular fluid (WFF): n: 679, and gentamicin sulphate $\left(50 \mu \mathrm{g} / \mathrm{cm}^{3}\right)$ under sterile mineral oil. The medium was adjusted to $\mathrm{pH} 7.4$ and an osmolarity of $295 \pm 5 \mathrm{mOs} / \mathrm{L}$. The microdroplets were prepared in sterile $60 \mathrm{~mm}$ disposable culture plates and covered with $6 \mathrm{ml}$ of mineral oil. The COCs were incubated

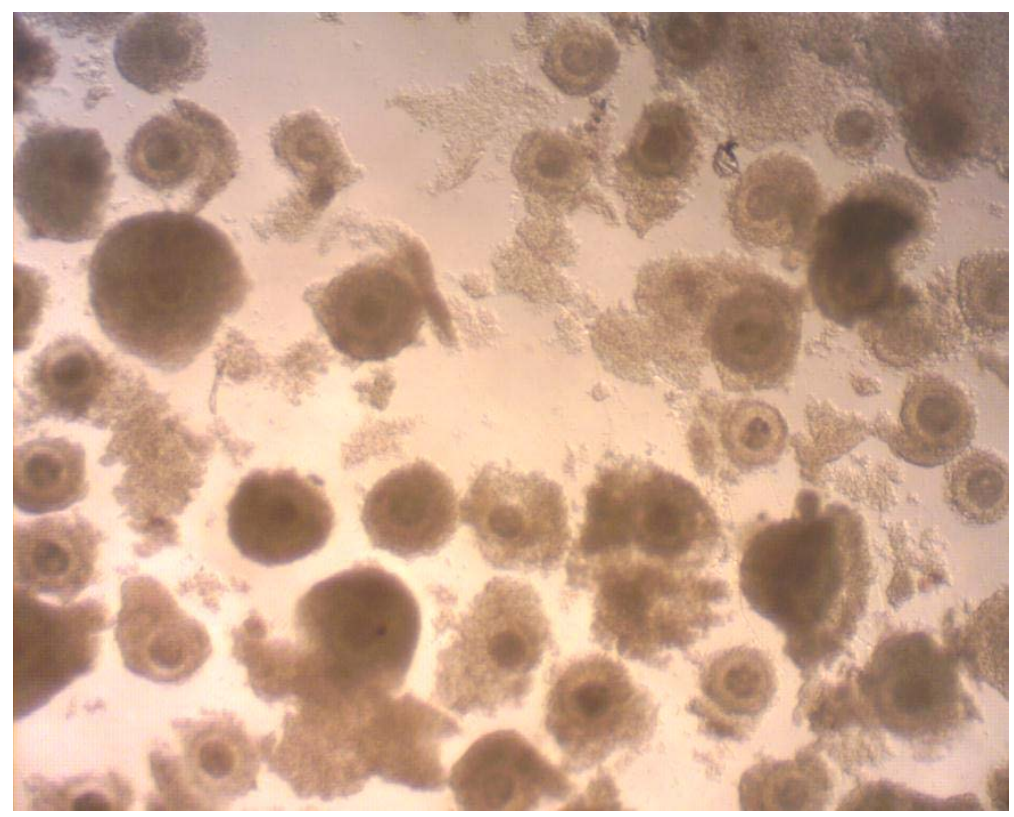

Figure 1. Obtention and classification oocytes. 
for 22 or 26 hours at $38.5^{\circ} \mathrm{C}$ in a $\mathrm{CO}_{2}$ incubator $\left(5 \% \mathrm{CO}_{2}\right.$ in air with $90 \%-95 \%$ relative humidity). After the maturation period, the expansion rate (fully expanded cumulus-oocyte complexes) was recorded and considered cytoplasmic maturation according to [29] [30]. Then 10\% of COCs from each experiment were used for staining to check for maturation, washed by PBS with hyaluronidase $\left(1 \mathrm{mg} / \mathrm{cm}^{3}\right)$, and vortexed for 10 minutes. Next, the denuded oocytes were fixed in ethanol: acetic acid $(3: 1 \mathrm{v} / \mathrm{v})$ and stained with $1 \%$ aceto-orcein for microscopic evaluation at $\times 400$ (Zeiss model Axiovert 135) of the first polar corpuscle and metaphase II. The oocytes that presented the first polar corpuscle and were in the metaphase II stage were considered mature.

\section{In vitro fertilization}

Spermatozoa were prepared from frozen-thawed semen and treated by the swim-up procedure in Hams medium for 1 hour. The pellet obtained after centrifugation of the supernatant was resuspended to a final concentration of $2 \times$ $10^{6} \mathrm{~cm}^{3}$ in the fertilization medium, consisting of Tyrode albumin lactate pyruvate supplemented with $0.2 \mathrm{mM}$ penicillamine, $0.1 \mathrm{mM}$ hypotaurine, and 0.01 $\mathrm{mM}$ heparin. Insemination was performed in $50 \mu \mathrm{L}$ drops of fertilization medium under mineral oil (5 oocytes per drop) at $38.5^{\circ} \mathrm{C}$ under humidified $5 \% \mathrm{CO}_{2}$ in air (for 18 hours) [30]. The COCs were washed by PBS with hyaluronidase (1 $\mathrm{mg} / \mathrm{cm}^{3}$ ) and vortexed for 10 minutes Next, the denuded oocytes were fixed in ethanol: acetic acid $(3: 1 \mathrm{v} / \mathrm{v})$ and stained with $1 \%$ aceto-orcein for microscopic evaluation at $\times 400$ (Zeiss model Axiovert 135) to check for the appearance of the second polar corpuscle as evidence of fertilized oocytes.

Statistical analysis

For each of the three variables under analysis (oocytes with cumulus expansion, oocytes with extrusion of the first polar corpuscle, oocytes with extrusion of the second polar corpuscle IVF), tests of homogeneity of proportions were carried out for the four treatments performed using a Chi Square test with a significance level $\mathrm{a}=5 \%$. Once differences were detected, Chi Square tests of pairs of interest ratios were performed (AFF: 22 hours vs 26 hours; WFF: 22 hours vs 26 hours; AFF 22 hours vs WFF 22 hours and AFF 26 hours vs WFF 26 hours) adjusting the significance level to a/4. InfoStat software was used [31]. The InfoStat software was used [31].

\section{Results}

The results showed of total oocytes, oocytes with extrusion of the first polar corpuscle, oocytes with cumulus expansion and fertilization rate (with extrusion of the second polar corpuscle). The percentage of cumulus expansion was $92.9 \%$, the percentage of mature oocytes was $92.1 \%$ (extrusion of the first polar corpuscle), and the percentage of fertilization (extrusion of the second polar corpuscle) was 79.45\%. The higher percentages of cumulus expansion, extrusion of the first polar corpuscle, and extrusion of the second corpuscle showed maturation, and fertilization of the oocyte after 26 hours of culture with the addition of follicular fluid (Table 1). 
Table 1. Total oocytes, cumulus expansion, maturation rate, and fertilization rate.

\begin{tabular}{cccc}
\hline $\begin{array}{c}\text { Recovered } \\
\text { oocytes }\end{array}$ & $\begin{array}{c}\text { Oocytes with } \\
\text { cumulus } \\
\text { expansion }\end{array}$ & $\begin{array}{c}\text { Oocytes with } \\
\text { extrusion of the } \\
\text { first polar corpuscle }\end{array}$ & $\begin{array}{c}\text { Oocytes with } \\
\text { extrusion of the second } \\
\text { polar corpuscle IVF }\end{array}$ \\
\hline 341 AFF & $63.92 \%$ & $72.01 \%$ & $62.38 \%$ \\
(22 hours) & $(218)$ & $(157)$ & $(136)$ \\
320 WFF & $59.68 \%$ & $67.53 \%$ & $53.40 \%$ \\
(22 hours) & $(191)$ & $(129)$ & $(102)$ \\
356 AFF & $92.9 \%$ & $92.1 \%$ & $79.45 \%$ \\
(26 hours) & $(331)$ & $(305)$ & $(263)$ \\
323 WFF & $71.82 \%$ & $77.15 \%$ & $65.08 \%$ \\
(26 hours) & $(232)$ & $(179)$ & $(151)$ \\
\hline
\end{tabular}

After the analysis of the 3 variables, using the Chi square test of homogeneity of variances, differences between treatments were detected in all of them.

After making four comparisons (adjusting the alpha):

1) AFF-22 hours vs 26 hours (for AFF 22 hours and 26 hours were compared), in all variables differences were detected.

2) WFF-22 hours vs 26 hours (for WFF 22 hours and 26 hours were compared), in all variables differences were detected.

3) AFF- 22 hours vs WFF 22 hours, in none of the variables differences were detected.

4) AFF-26 hours vs WFF 26 hours in all the variables differences were detected (Figures 2-5).

\section{Discussion}

Mammals contain follicles that are in different stages of development, and only a small proportion of them will be used during the animal's reproductive life. The collection of oocytes recovered from slaughterhouse ovaries or live animals make it possible to recover and profit from non-ovulatory follicles, which under physiological conditions could turn into atretic follicles. The most economical and common way to obtain oocytes is from slaughterhouse ovaries. Accordingly, there is robust knowledge about the factors that affect the collection of ovaries. [6] [32].

The relationship between suitable and unsuitable oocytes per ovary is directly associated with three variables: ovary collection and transport, the methods and instruments used to obtain the oocytes, and the correct selection criteria. Thus, the adequate training of the operator and the quality and origin of the original material (ovaries) are important in evaluating results [33].

In vitro maturation systems must ensure that the resulting oocyte normally completes the first reductional division and is capable of being fertilized, giving rise to a competent zygote that can continue its development after transfer [33].

Reference [34] described many aspects of oocyte maturation that should be considered during their cultivation: nuclear maturation, the ability to be fertilized, 


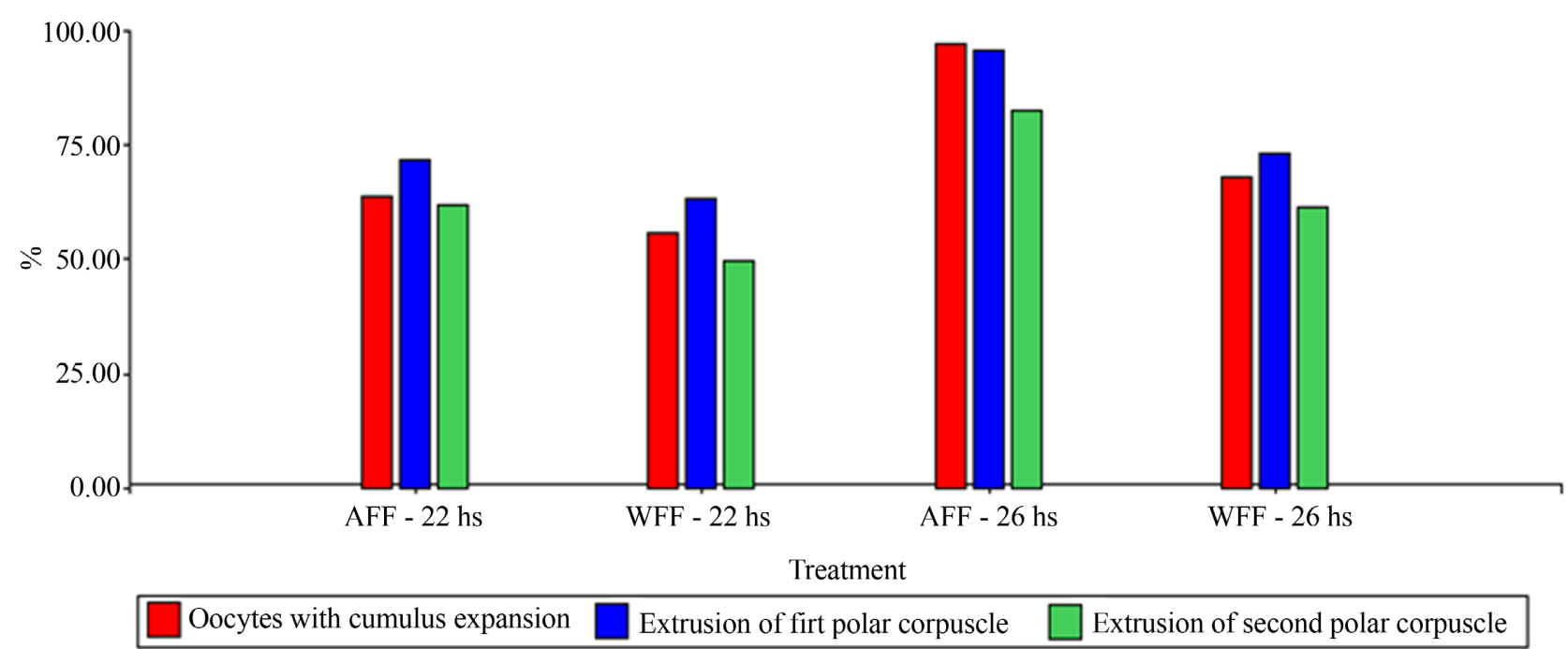

Figure 2. Total oocytes, cumulus expansion, maturation rate, and fertilization rate.

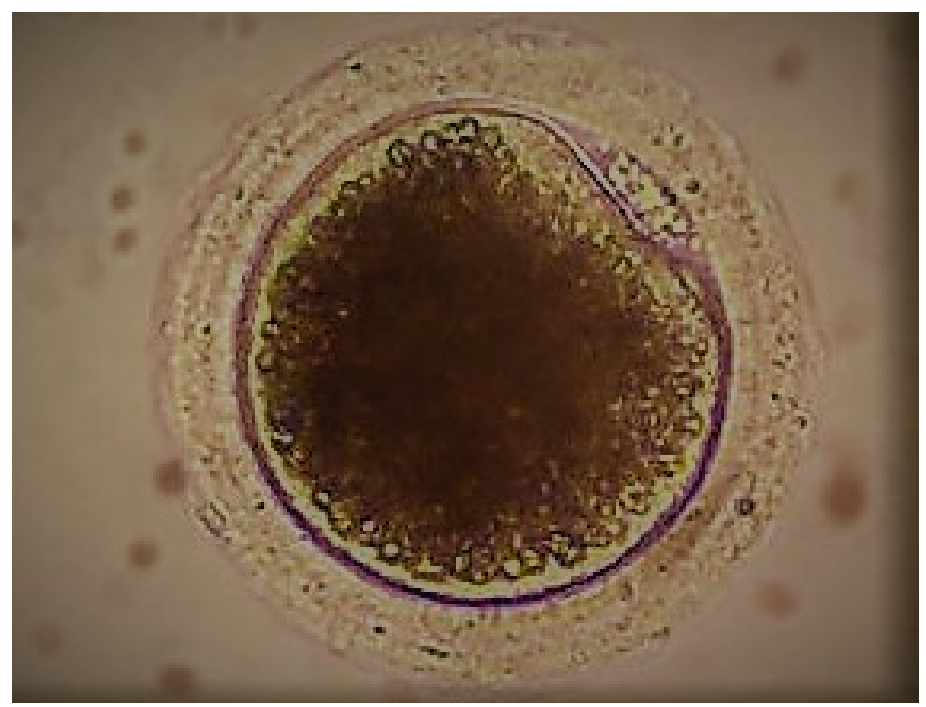

Figure 3. In vitro maduration: Oocytes with extrusion of the first polar corpuscle.

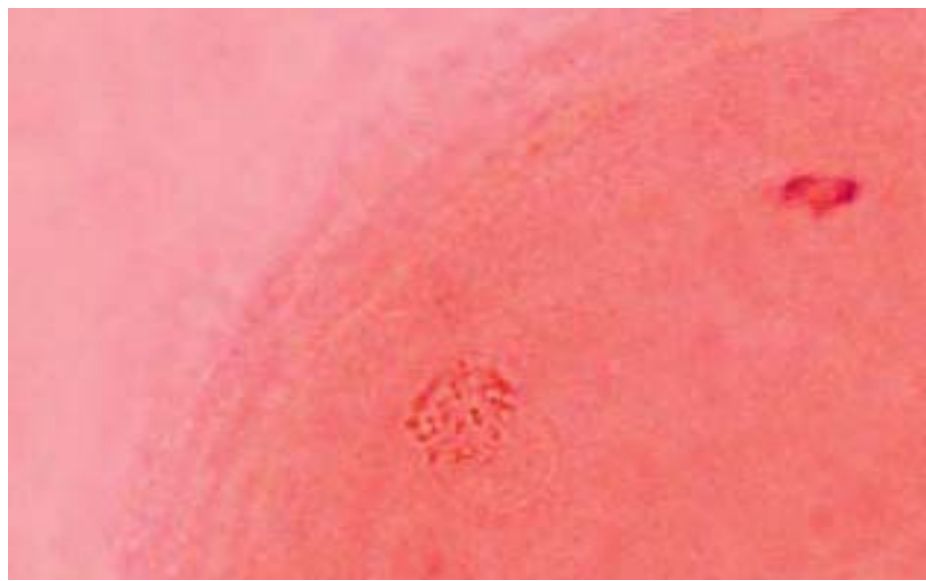

Figure 4. Metaphase II and extrusion of the first polar corpuscle: stained with $1 \%$ aceto-orcein. 


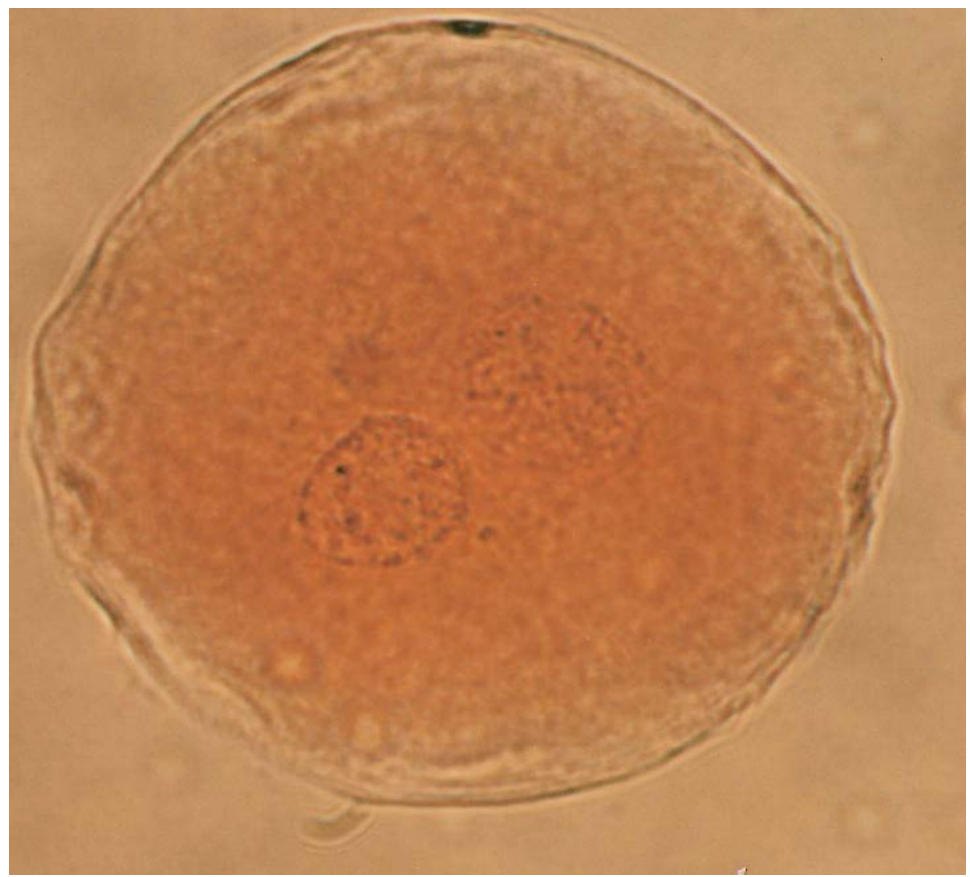

Figure 5. In vitro fertilization: Extrusion second polar corpuscle and pronuclei: stained with $1 \%$ aceto-orcein.

and the ability to continue their development. Reference [4] stated that the competence of oocyte maturation is influenced by several factors such as ovarian status, follicle size, collection method, oocyte quality, culture conditions, and time between collection and processing. According to our results and those of other researchers [20] [25] [26] [35] [36], other aspects to be taken into account are transport temperature from slaughterhouse to laboratory and aspiration pressure during collection, oocyte quality [9] [37] [38], maturation time [39], culture medium with added follicular fluid that contains electrolytes, proteins, hormones such as testosterone, $\mathrm{E}_{2}$ and $\mathrm{P}_{4}$, growth factors, and nutrients [11] [40] [41].

As mentioned above, FF is the product of the transfer of blood plasma components through the blood-follicular barrier and of the metabolism of theca and granulosa cells [23] [24]. It corresponds to a complex mixture of electrolytes, proteins, hormones, growth factors, steroids, nutrients and other molecules [20] [24] [25] [35] and it maintains a proper environment for growth and maturation of oocytes, while meeting the nutritional requirements of the growing oocytes [26]. According other results [40], the addition of follicular fluid to the medium yielded $78.7 \%$ maturation, as opposed to media supplemented with fetal bovine serum, which resulted in $69.3 \%$ maturation. Reference [42] in pigs showed that the FF promoted cumulus expansion (84\%) and male pronucleus formation $(62 \%)$ of in vitro fertilized and matured oocytes.

The authors of other studies in pigs and cattle have reported that the supplementation of the media with FF can promote the maturation and/or fertilization of oocytes and their subsequent embryonic development [43] [44]. However, it 
should be mentioned that most of these studies have been carried out with media in the presence of serum or hormones, so the results obtained would not necessarily reflect the effect of FF, which could be masked by the action of these other components [45].

\section{Conclusion}

Despite the different opinions, our results showed that the effects can be observed after 26 hours of in vitro maturation with the AFF (extrusion of the first polar corpuscle), with a maturation percentage of $92.1 \%$ and a fertilization percentage (extrusion of the second polar corpuscle) of $79.45 \%$. Concerning the oocytes incubated for 26 hours in a non-supplemented maturation medium, the WFF (extrusion of the first polar corpuscle) was $77.15 \%$ and the fertilization percentage (extrusion of the second polar corpuscle) was $65.08 \%$. The incorporation of $\mathrm{FF}$ to the maturation medium satisfies the nutritional needs of the growing oocytes. The addition of FF may be a biological strategy for development in vitro embryos.

\section{Acknowledgements}

The authors wish to thank Professor Wilson Espinosa for correcting the manuscript in English and Lic. Mg. Nora Abbiati for statistical analysis.

\section{Conflicts of Interest}

The authors declare no conflicts of interest regarding the publication of this paper.

\section{References}

[1] Parrish, J., Susko-Parrish, J., Leibfried-Rutledge, M., Critser, E., Eyestone, W. and First, N. (1986) Bovine in Vitro Fertilization with Frozen-Thawed Semen. Theriogenology, 25, 591-600. https://doi.org/10.1016/0093-691X(86)90143-3

[2] Hosseini, S.M., Moulavi, F., Hajian, M., Abedi, P., Forouzanfar, M. and Ostad Hosseini, S. (2008) Highly Efficient in Vitro Production of Bovine Blastocyst in Cell-Free Sequential Oviductal Fluid vs. TCM199 Vero Cell Co-Culture System. International Journal of Fertility and Sterility, 2, 66-73.

[3] Pirestani, A., Hosseini, D.V.M., Mahdi, H., Mohsen, F., Fariba, M., Parvaneh, A., Hamid, G., Abdolhossein, Sh., Ahmad, V.T. and Mohammad, H.N.E. (2012) Effect of Ovarian Cyclic Status on in Vitro Embryo Production in Cattle. International Journal of Fertility and Sterility, 4, 172-175.

[4] Mahmoud, K.Gh.M. and El-Naby Al-Shimaa, H.H. (2013) Factors Affecting Buffalo Oocytes Maturation. Global Veterinaria, 11, 497-510.

[5] Hussein, T., Thompson, J. and Gilchrist, R. (2006) Oocyte-Secreted Factors Enhance Oocyte Developmental Competence. Development Biology, 296, 514-521. https://doi.org/10.1016/j.ydbio.2006.06.026

[6] Keskintepe, L., Darwish, G.M., Kenimer, A.T. and Brackett, B.G. (1994) Term Development of Caprine Embryos Derived from Immature Oocytes in Vitro. Theriogenology, 42, 527-535. https://doi.org/10.1016/0093-691X(94)90690-K

[7] Park, Y., Kim, S., Kim, J., Park, H. and Byum, M. (2005) The Effects of Duration of 
in Vitro Maturation of Bovine Oocytes on Subsequent Development, Quality and Transfer of Embryos. Theriogenology, 64, 123-134.

https://doi.org/10.1016/j.theriogenology.2004.11.012

[8] Sirard, M., Richard, F., Blondin, P. and Robert, C. (2006) Contribution of the Oocyte to Embryo Quality. Theriogenology, 65, 126-136.

https://doi.org/10.1016/j.theriogenology.2005.09.020

[9] Di Francesco, S., Boccia, L., Di Palo, R., Esposito, G., Attanasio, L., De Rosa, A. and Gasparrini, B. (2007) Influence of Temperature and Time During Ovary Transportation on in Vitro Embryo Production Efficiency in the Buffalo Species (Bubalus bubalis). Italian Journal of Animal Science, 6, 755-758.

https://doi.org/10.4081/ijas.2007.s2.755

[10] Pavlok, A., Lucas-Hahn, A. and Niemann, H. (1992) Fertilization and Developmental Competence of Bovine Oocytes Derived from Different Categories of Antral Follicles. Molecular Reproduction Development, 31, 63-67.

https://doi.org/10.1002/mrd.1080310111

[11] Chauhan, M.S., Palta, P., Das, S.K., Katiyar, P.K. and Madan, M.L. (1997) Replacement of Serum and Hormone Additives with Follicular Fluid in IVM Media: Effects of Maturation, Fertilization and Subsequent Development of Buffalo Oocytes in $\mathrm{Vi}$ tro. Theriogenology, 48, 461-469. https://doi.org/10.1016/S0093-691X(97)00255-0

[12] Puri, G., Chaudhary, S.S., Singh, V. and Sharma, A.K. (2015) Effects of Fetal Bovine Serum and Estrus Buffalo Serum on Maturation of Buffalo (Bubalus bubalis) Oocytes in Vitro. Veterinary World, 8, 143-146. https://doi.org/10.14202/vetworld.2015.143-146

[13] Leisinger, C.A., Coffman, E.A., Coutinho da Silva, M.A., Forshey, B.S. and Pinto, C.R.F. (2014) Factors Affecting in Vitro Maturation of Alpaca (Lama Paco) Oocytes. Animal Reproduction Science, 150, 70-75. https://doi.org/10.1016/j.anireprosci.2014.08.011

[14] Tan, S.J. and Lu, K.H. (1990) Effects of Different Oestrus Stages of Ovaries and Sizes of Follicles on Generation of Bovine Embryos in Vitro. Theriogenology, 33, 335. https://doi.org/10.1016/0093-691X(90)90759-M

[15] Tartaglione, C.M. and Ritta, M.N. (2004) Prognostic Value of Spermatological Parameters as Predictors of "in Vitro" Fertility of Frozen-Thawed Bull Semen. Theriogenology, 62, 1245-1252. https://doi.org/10.1016/j.theriogenology.2004.01.012

[16] Blondin, P. and Sirard, M.A. (1995) Oocyte and Follicular Morphology as Determining Characteristics for Developmental Competence in Bovine Oocytes. Molecular Reproduction Development, 41, 54-62. https://doi.org/10.1002/mrd.1080410109

[17] Leibfried, L. and First, N.L. (1979) Characterization of Bovine Follicular Oocytes and Their Ability to Mature in Vitro. Journal of Animal Science, 48, 76-86.

https://doi.org/10.2527/jas1979.48176x

[18] Abd Ellah, M.R., Hussein, H.A. and Derar, D.R. (2010) Ovarian Follicular Fluid Constituents in Relation to Stage of Estrus Cycle and Size of the Follicle in Buffalo. Veterinary World, 3, 263-267.

[19] Yoon, K.W., Shin, T.Y., Park, J.I., Roh, S., Lim, J.M. and Lee, B.C. (2001) Development of Porcine Oocytes from Preovulatory Follicles of Different Sizes after Maturation in Media Supplemented with Follicular Fluids. Reproduction, Fertility and Development, 12, 133-139. https://doi.org/10.1071/RD00027

[20] Germoush, M.O., et al. (2018) Effects of Follicular Fluid on Developmental Competence and Gene Expression of in Vitro Fertilized Sheep Embryos, Pakistan. Journal 
Zoology, 50, 1267-1277. https://doi.org/10.17582/journal.pjz/2018.50.4.1267.1277

[21] Blaszczyk, B., Stankiewicz, T., Udala, J., Gaczarzewicz, D., Lasota, B. and Blaszczyk, P. (2006) Free Thyroid Hormones and Cholesterol in Follicular Fluid of Bovine Ovaries. Bulletin of the Veterinary Institute in Pulawy, 50, 189-193.

[22] Bijttebier, J., Van Soom, A., Meyer, E., Mateusen, B. and Maes, D. (2008) Preovulatory Follicular Fluid during in Vitro Maturation Decreases Polyspermic Fertilization of Cumulus Intact Porcine Oocytes: In Vitro Maturation of Porcine Oocytes. Theriogenology, 70, 715-724. https://doi.org/10.1016/j.theriogenology.2008.04.046

[23] Ducolomb, Y., González-Márquez, H., Fierro, R., Jiménez, I., Casas, E., Flores, D., Bonilla, E., Salazar, Z. and Betancourt, M. (2013) Effect of Porcine Follicular Fluid Proteins and Peptides on Oocyte Maturation and Their Subsequent Effect on in $\mathrm{Vi}$ tro Fertilization. Theriogenology, 79, 896-904. https://doi.org/10.1016/j.theriogenology.2013.01.024

[24] Klumpp, A.M. (2004) The Effect of Holding Bovine Oocytes in Follicular Fluid on Subsequent Fertilization and Embryonic Development. LSU Master's Theses, 2563. https://digitalcommons.lsu.edu/gradschool_theses/2563

[25] Ito, M., Iwata, H., Kitagawa, M., Kon, Y., Kuwayama, T. and Monji, Y. (2008) Effect of Follicular Fluid Collected from Various Diameter Follicles on the Progression of Nuclear Maturation and Developmental Competence of Pig Oocytes. Animal Reproduction Science, 106, 421-430. https://doi.org/10.1016/j.anireprosci.2007.06.003

[26] Ali, S., Ahmad, N., Akhtar, N., Zia-Ur-Rahman and Noakes, D.E. (2008) Metabolite Contents of Blood Serum and Fluid from Small and Large Size Follicles in Dromedary Camels during the Peak and the Low Breeding Seasons. Animal Reproduction Science, 108, 446-456. https://doi.org/10.1016/j.anireprosci.2007.10.001

[27] Avery, B., Strøbech, L., Jacobsen, T., Bøgh, I.B. and Greve, T. (2003) In Vitro Maturation of Bovine Cumulus-Oocyte Complexes in Undiluted Follicular Fluid: Effect on Nuclear Maturation, Pronucleus Formation and Embryo Development. Theriogenology, 59, 987-999. https://doi.org/10.1016/S0093-691X(02)01139-1

[28] Nasroallah, M.K. (2014) The Effect of Corpus Luteum on Hormonal Composition of Follicular Fluid from Different Sized Follicles and Their Relationship to Serum Concentrations in Dairy Cows. Asian Pacific Journal of Tropical Medicine, 7, 282-288. https://doi.org/10.1016/S1995-7645(14)60247-9

[29] El-Ratel, I.T. and Fouda, S.F. (2016) Potentiality of Epidermal Growth Factor or/and Cysteamine in Maturation Medium on in Vitro Rabbit Embryo Production and Apoptosis. Global Veterinaria, 6, 505-512.

[30] Yang, N.S., Lu, K.H. and Gordon, I. (1990) In Vitro Fertilization (IVF) and Culture (IVC) of Bovine Oocytes from Stored Ovaries. Theriogenology, 33, 352. https://doi.org/10.1016/0093-691X(90)90776-P

[31] Di Rienzo, J.A., Casanoves, F., Balzarini, M.G., Gonzalez, L., Tablada, M., Robledo, C.W. (2018) InfoStat versión 2018. Centro de Transferencia InfoStat, FCA, Universidad Nacional de Córdoba, Argentina. http://www.infostat.com.ar

[32] Leibfried-Rutledge, M.L., Critser, E.S., Parrish, J.J. and First, N.L. (1989) In Vitro Maturation and Fertilization of Bovine Oocytes. Theriogenology, 31, 61-74. https://doi.org/10.1016/0093-691X(89)90564-5

[33] Bracket, B. and Zuelke, K. (1993) Analysis of Factors Involved in the in Vitro Production of Bovine Embryos. Theriogenology, 39, 43-64. https://doi.org/10.1016/0093-691X(93)90023-X

[34] Auclair, S., Uzbekov, R., Elis, S., Sanchez, L., Kireev, I., Lardic, L., Dalvies-Tran, R. 
and Uzbekova, S. (2013) Absence of Cumulus Cells During in Vitro Maturation Affects Lipid Metabolism in Bovine Oocytes. Endocrinoly and Metabolism, 304, E599-E613. https://doi.org/10.1152/ajpendo.00469.2012

[35] Macaulay, A.D., et al. (2016) Cumulus Cell Transcripts Transit to the Bovine Oocyte in Preparation for Maturation. Biology of Reproduction, 94, 1-11.

https://doi.org/10.1095/biolreprod.114.127571

[36] Covelo, I., Puente, M. and Tartaglione, C.M. (2019) Culture Medium and Oocyte Quality on Bovine Oocyte Maturation and in Vitro Fertilization. Modern Agricultural Science and Technology, 5, 15-20. https://doi.org/10.15341/mast(2375-9402)/03.05.2019/002

[37] Lasienë, K., Vitkus, A., Valanèiûtë, A. and Lasys, V. (2009) Morphological Criteria of Oocyte Quality. Medicina (Kaunas), 45, 509-515. http://medicina.kmu.lt https://doi.org/10.3390/medicina45070067

[38] Vassena, R., Mapletoft, R.J., Allodi, S., Singh, J. and Adams, G.P. (2003) Morphology and Developmental Competence of Bovine Oocytes Relative to Follicular Status. Theriogenology, 60, 923-932. https://doi.org/10.1016/S0093-691X(03)00101-8

[39] Báez Contreras, F.G., Landinez Aponte, J.A., Hernández Fonseca, H.J. and Villamediana Monreal, P.C. (2010) Evaluación del desarrollo embrionario de ovocitos bovinos madurados y fecundados in Vitro obtenidos a partir de hembras mestizas Revista. Facultad Agronomía, 27, 460.

[40] El-Nasser Mohammed, A. (2019) Effects of Follicular Fluid Components on Oocyte Maturation and Embryo Development in Vivo and in Vitro. Advances in Animal and Veterinary Sciences, 7, 346-355.

https://doi.org/10.17582/journal.aavs/2019/7.5.346.355

[41] Castro Modesto, T.M. (2018) Efecto del Fluido Folicular de Alpaca en la Maduración Ovocitaria in vitro de Alpaca (Vicugna pacos). Tesis. Universidad Nacional Mayor de San Marcos Universidad del Perú. Decana de América. Facultad de Ciencias Biológicas Escuela Profesional de Genética y Biotecnología Cybertesis. https://hdl.handle.net/20.500.12672/9692

[42] Daen, F.P., Sato, E., Naito, K. and Toyoda, Y. (1994) The Effect of Pig Follicular Fluid Fractions on Cumulus Expansion and Male Pronucleus Formation in Porcine Oocytes Matured and Fertilized in Vitro. Journal Reproduction and Fertility, 101, 667-673. https://doi.org/10.1530/jrf.0.1010667

[43] Algriany, O., Bevers, M., Schoevers, E., Colenbrander, B. and Dieleman, S. (2004) Follicle Size-Dependent Effects of Sow Follicular Fluid on in Vitro Cumulus Expansion, Nuclear Maturation and Blastocyst Formation of Sow Cumulus Oocytes Complexes. Theriogenology, 62, 1483-1497. https://doi.org/10.1016/j.theriogenology.2004.02.008

[44] Tatemoto, H., Muto, N., Sunagawa, I., Shinjo, A. and Nakada, T. (2004) Protection of Porcine Oocytes against Cell Damage Aused by Oxidative Stress during in Vitro Maturation: Role of Superoxide Dismutase Activity in Porcine Follicular Fluid. Biology of Reproduction, 71, 1150-1157. https://doi.org/10.1095/biolreprod.104.029264

[45] Agung, B., Piao, Y., Fuchimoto, D., Senbon, S., Onishi, A., Otoi, T. and Nagai, T. (2010) Effects of Oxygen Tension and Follicle Cells on Maturation and Fertilization of Porcine Oocytes during in Vitro Culture in Follicular Fluid. Theriogenology, 73, 893-899. https://doi.org/10.1016/j.theriogenology.2009.11.013 